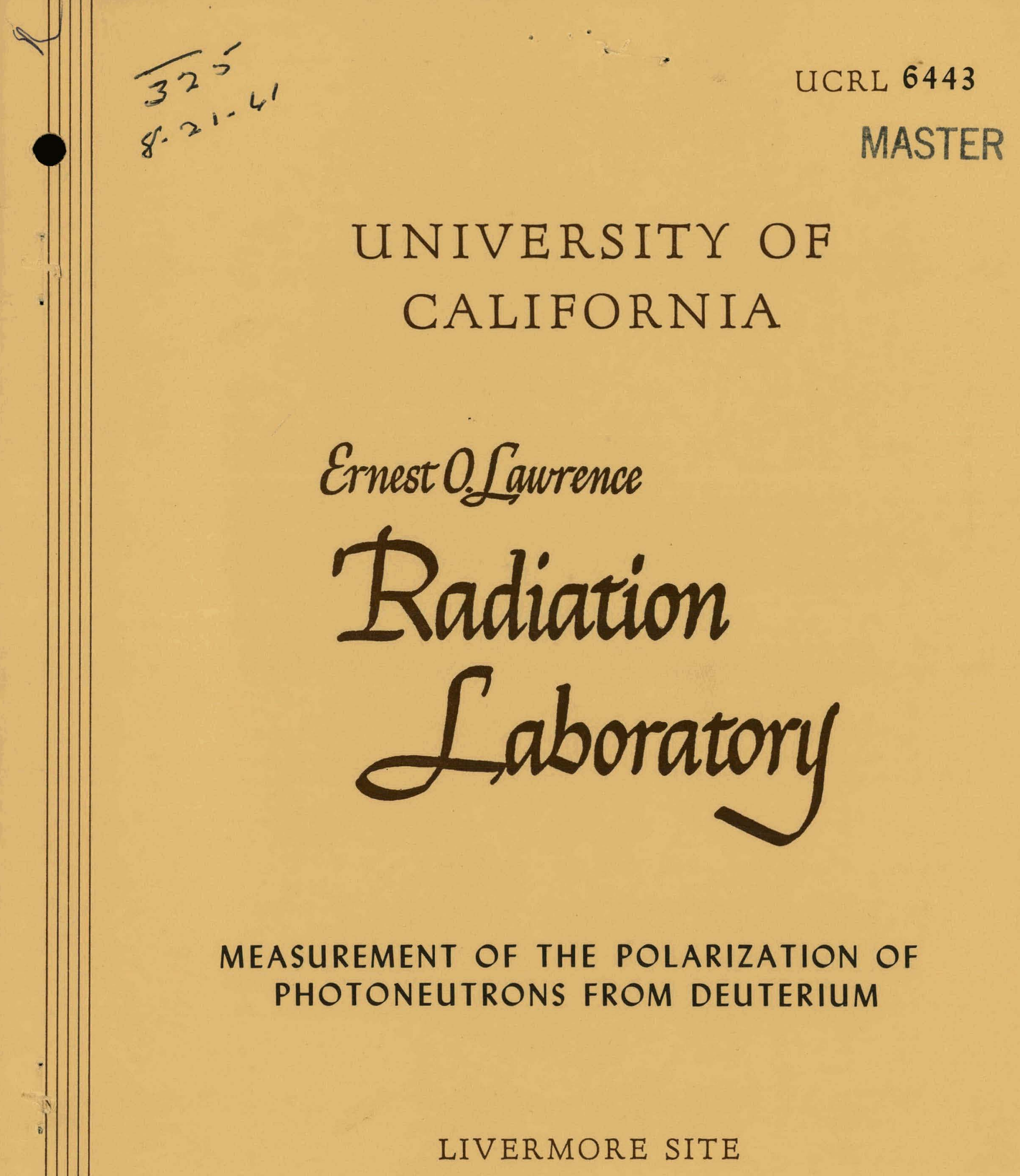




\section{DISCLAIMER}

This report was prepared as an account of work sponsored by an agency of the United States Government. Neither the United States Government nor any agency Thereof, nor any of their employees, makes any warranty, express or implied, or assumes any legal liability or responsibility for the accuracy, completeness, or usefulness of any information, apparatus, product, or process disclosed, or represents that its use would not infringe privately owned rights. Reference herein to any specific commercial product, process, or service by trade name, trademark, manufacturer, or otherwise does not necessarily constitute or imply its endorsement, recommendation, or favoring by the United States Government or any agency thereof. The views and opinions of authors expressed herein do not necessarily state or reflect those of the United States Government or any agency thereof. 


\section{DISCLAIMER}

Portions of this document may be illegible in electronic image products. Images are produced from the best available original document. 
UCRL -6443

Physics, UC- 34

TID -4500 ( 16 th Ed.)

\section{UNIVERSITY OF CALIFORNIA}

Lawrence Radiation Laboratory

Livermore, California

Contract No. W-7405-eng-48

\section{MEASUREMENT OF THE POLARIZATION OF PHOTONEUTRONS}

FROM DEUTERIUM

Frederick V. Martin

(Thesis)

and

Walter John, Jr。

12 May 1961 
Printed in USA: Price $\$ 1.00$. Available from the Office of Technical Services, Department of Commerce, Washington $25, \mathrm{D}$. C. 


\title{
MEASUREMENT OF THE POLARIZATION OF PHOTONEUTRONS
}

\section{FROM DEUTERIUM}

\author{
Frederick V. Martin and Walter John, Jr. \\ Lawrence Radiation Laboratory, University of California \\ Livermore, California
}

12 May 1961

\begin{abstract}
The polarization of the neutrons produced by photodisintegration of deuterium by 2.75-Mev gamma rays has been measured and the results compared to theoretical predictions. The photoneutrons were taken at five gammarày-neutron angles between $45^{\circ}$ and $135^{\circ}$ in the laboratory and scattered from magnesium which has a broad resonance at these neutron energies. The polarization was determined from the asymmetry in the left-right scattering from magnesium: The neutrons are found to be negatively polarized as predicted. The magnitude of the polarization and the dependence on the gammaray-neutron angle are found to be in agreement with the theory within experimental error.
\end{abstract}




\title{
MEASUREMENT OF THE POLARIZATION OF PHOTONEUTRONS
}

\section{FROM DEUTERIUM *}

\author{
Frederick V. Martin and Walter John; Jr. \\ Lawrence Radiation Laboratory, University of California \\ Livermore, California
}

\section{INTRODUCTION}

In this paper, we present the results of an experiment to measure the polarization of the neutrons from the reaction $D(\gamma, n) p$ using 2.75-Mev gamma rays. The only other experiment ${ }^{l}$ on the polarization of photonucleons which has appeared in the literature was performed at $240 \mathrm{Mev}$ where theories are not available at present.

That the nucleons produced by photodisintegration of deuterium should be polarized was first pointed out by Rosentsveig ${ }^{2}$ and independently by Czyz and Sawicki. ${ }^{3}$ At low gamma-ray energies, the polarization arises from an interference between the electric dipole transition and the spin-flipping magnetic dipole transition. The spin of the outgoing neutron (or proton) is normal to the reaction plane defined by the momenta of the incoming gamma ray and the outgoing neutron.

Calculations of the polarization to be expected at various gamma-ray energies have been published by several authors. ${ }^{4-9,20}$ At medium gammaray energies, the polarization was found to be sensitive to the $n-p$ wave functions as well as to the interaction with the electromagnetic field. For gammaray energies within a few Mev of threshold, the $n-p$ interaction depends only on the depth and range of the potential and can be treated in the effective-range 
approximation. The polarization at low energies still depends on the as umptions concerning the electromagnetic transitions. Thus, experimental meas urements of the polarization would, for medium gamma-ray energies, supply information concerning the $\mathrm{n}-\mathrm{p}$ system and the interaction of nucleons with the electromagnetic field. At low energies, polarization measurements would test the consistency of the current interpretation of the electromagnetic transitions derived mainly trom the difierential cross sections for the phuludis= integration of the deuteron.

\section{POLARIZATION AT VERY LOW GAMMA-RAY ENERGIES}

The photodisintegration of the deuteron just above threshold is usually assumed to proceed predominantly by dipole transitions. The transitions are:

$$
\begin{array}{ll}
{ }^{3} \mathrm{~S} \rightarrow{ }^{3} \mathrm{P} & \text { electric dipole } \\
{ }^{3} \mathrm{~S} \rightarrow{ }^{1} \mathrm{~S} & \text { magnetic dipole }
\end{array}
$$

The differential cross section is written

$$
\frac{d \sigma}{d \Omega}=a+b \sin ^{2} \theta
$$

where the isotropic term, a, results from the magnetic dipole transition and b derives from the electric dipole transition.

Rosentsveig ${ }^{4}$ treated the polarization at low energies in the zero-range approximation. Kawaguchi ${ }^{6}$ arrived at polarization formulae containing the coefficients of the angular distribution for photodisintegration and the nucleonnucleon scattering-phase shifts. The derivation is based on the unitarity of the $\mathbf{S}$ matrix which results in a connection between scattering and photodis integration. Kawaguchi assumed that, at low energies, only dipole transitions took place and that no noncentral force was involved. Then the photoproton polarization for unpolarized gamma rays and unpolarized deuterons was given by 


$$
P= \pm \frac{(2 a b / 3)^{1 / 2} \sin \theta \sin \left[\delta\left({ }^{l} S\right)-\delta\left({ }^{3} P\right)\right]}{a+b \sin ^{2} \theta}
$$

where $a$ and $b$ are the angular distribution coefficients mentioned above, and $\delta\left({ }^{1} S\right), \delta\left({ }^{3} P\right)$, are the singlet-S and triplet-P $n-p$ scattering-phase shifts. At $2.75 \mathrm{Mev} \delta\left({ }^{3} \mathrm{P}\right)$ is negligible compared to $\delta\left({ }^{l} \mathrm{~S}\right)$. The ambiguity in the sign of the polarization is a consequence of the mode of derivation of the expression. By dividing numerator and denominator of the fraction by $b$, one finds that $P$ depends only on the ratio $a / b$ and on $\delta\left({ }^{l} S\right)$. The polarization is symmetric about $90^{\circ}$ in the center of mass. $P$ is zero at $0^{\circ}$ and $180^{\circ}$, maximum at $\sin \theta_{\max }=\sqrt{a / b}$, and has a shallow minimum at $90^{\circ}$. Kawaguchi derived the above formula for $P$ for the proton, however, at low energies, the neutron polarization is given by the same expression.

Kramer and Müller ${ }^{9}$ have treated the low-energy polarization extensively in the effective-range approximation. They write

$$
P \cdot \frac{d \sigma}{d \Omega}=\left(\gamma_{0}+\gamma_{1} \cos \theta+\gamma_{2} \cos ^{2} \theta\right) \sin \theta \text {. }
$$

At $2.75 \mathrm{Mev}, \gamma_{2}$ is negligible, while $\gamma_{1}$ is approximately $2 \%$ of $\gamma_{0}$. For the accuracy to which the present experiment can be made, the equation may be written:

$$
P \cdot \frac{d \sigma}{d \Omega}=\gamma_{0} \sin \theta
$$

The expression above is the same as that derived by Kawaguchi where

$$
\gamma_{0}=(2 a b / 3)^{1 / 2} \sin \delta\left({ }^{l} S\right)
$$

However, the ambiguity in sign is removed. Kramer and Müller calculated $a, b$, and $\gamma_{0}$ at several energies from 3 to $1 \mathrm{l} \mathrm{Mev}$ and under various assumptions for the parameters of the effective-range theory. Kramer ${ }^{10}$ has also evaluated the polarization at $2.75 \mathrm{Mev}$ for comparison to this experiment. A plot of the polarization from this calculation is given in Fig. 9. 


\section{POLARIZATION EXPERIMENT USING 2.75-Mev GAMMA RAYS}

The difficulties in measuring the polarization at low energies are mainly. due to the small photodisintegration cross section of deuterium $(\sim \mathrm{mb})$ and the fairly low neutron polarization expected $(\sim 30 \%)$. That is, a strong source of gamma rays and an efficient polarization analyzer are required. In the present experiment, we have used the $2.75-\mathrm{Mev}$ gamma rays from a $\mathrm{Na}^{24}$ source to disintegrate the deuterium. The neutron polarization was determined from the left-right asymmetry in the scattering from magnesium. The entire feasibility of the experiment is due to the fortunate fact that the neutrons from a $\mathrm{Na}^{24}-\mathrm{D}$ source have energies which fall on a broad scattering resonance in magnesium having a high polarization-analyzing ability.

Radioactive sources have been used frequently in the past to supply gamma rays for the measurement of the photodisintegration cross sections of deuterium at low energies. A radioactive source has the advantage of providing nearly monochromatic gamma rays in contrast to the bremsstrahlung spectrum from an electron accelerator. $\mathrm{Na}^{24}$ is an excellent source for the present experiment. The 2.753-Mev gamma ray is the only gamma ray from $\mathrm{Na}^{24}$ of appreciable abundance above the $2.225-\mathrm{Mev}^{11}$ threshold for the photodisintegration of the deuteron. The gamma-ray energy is known to within l kev. ${ }^{12}$ The 15.0-hour half-life $e^{13}$ is known to better than $0.1 \mathrm{hr}$ and is convenient for the preparation of the source and for counting with the source. The neutron activation cross section of $0.54 \mathrm{~b}$ is sufficient to permit the preparation of large sources in available neutron fluxes. As mentioned above, the energies of the photoneutrons are crucial to the experiment. Because of the momentum of the center of mass in the laboratory system, the neutron energy depends on the angle between the incoming gamma ray and the outgoing neutron. 
For a $\mathrm{Na}^{24}-\mathrm{D}$ source, the neutron energy in the laboratory is given ${ }^{14}$ in terms of the laboratory angle by:

$$
E_{n}(k e v)=262+33 \cos \theta \text {. }
$$

Natural magnesium is composed of three isotopes: $\mathrm{Mg}^{24}(78: 6 \%)$, $\mathrm{Mg}^{25}(10.1 \%)$, and $\dot{\mathrm{Mg}}^{26}(11.3 \%)$. The total cross section for the scattering of neutrons from magnesium has been measured by Fields and $W$ alt, ${ }^{15}$ and recently by Newson et al. ${ }^{16}$ In the range from 15 to $370 \mathrm{kev}$, Newson et al. find a resonance at $260 \mathrm{kev}$ with a width of $75 \pm 15 \mathrm{kev}$ which they assign to $\mathrm{Mg}^{24}$. Comparison of the energy of this resonance to the energies of the $\mathrm{Na}^{24}-\mathrm{D}$ photoneutrons given in the equation above shows a remarkable match. The 260-kev level in $\mathrm{Mg}^{24}$ was assigned $\mathrm{J}^{\pi}=1 / 2^{-} . \mathrm{Mg}^{24}$ has another prominent resonance at $83 \mathrm{kev}$, assigned $\mathrm{J}^{\pi}=3 / 2^{-}$, a $\mathrm{p}$-wave level。 Since $\mathrm{Mg}^{24}$ has zero spin, the res,onances at $83 \mathrm{kev}$ and $260 \mathrm{kev}$ evidently correspond to p-wave scattering in the two neutron spin orientations. The total cross section at the peak of the 260-kev resonance is about $11 \mathrm{~b}$. The minor isotopes have cross section curves similar to that of $\mathrm{Mg}^{24}: \mathrm{Mg}^{25}$ has some undetermined structure in the region of 250 to $350 \mathrm{kev}$ and $\mathrm{Mg}^{26}$ has a wide resonance near $300 \mathrm{kev}$, assigned $\mathrm{J}^{\pi}=1 / 2^{-}$. The peak cross sections of the minor isotopes in the $300-\mathrm{kev}$ region are about $11 \mathrm{~b}$.

Recently, Elwyn, Lane, and Langsdorf 17,18 , have measured the leftright ratios of neutrons scattered from magnesium. They employed neutrons emerging at an angle of $51^{\circ}$ from the $\mathrm{Li}^{7}(\mathrm{p}, \mathrm{n}) \mathrm{Be}^{7}$ reaction. The polarization, $P_{1}$, of the neutron beam in the energy region in which we are interested was determined from the measured $\mathrm{P}_{1} \mathrm{P}_{2}$ for scattering from $\mathrm{Li}^{7}$ targets. The beam polarizations so determined were in agreement with those calculated directly from the magnesium measurements; there was some uncertainty due to the minor isotopes of magnesium. Elwyn, Lane, and Langsdorf analyzed 
their data to give the polarization, $P_{2}$, of the neutron scattering from natural magnesium from $206 \mathrm{kev}$ to $312 \mathrm{kev}, \mathrm{P}_{2}$ is quite large, varying from $89 \%$ at $240 \mathrm{kev}$ to $47 \%$ at $312 \mathrm{kev}$. The findings of Elwyn, Lane, and Langsdorf motivated our use of magnesium as a polarization analyzer which in turn made: the present experiment possible.

The scattering of polarized neutrons from $\mathrm{Mg}^{7.4}$ is analogous to the well-known caśe ${ }^{17}$ of scattering frun $\mathrm{He}^{4}$. Dutli are spin-scro nuclei $\left(\mathrm{Mg}^{24}\right.$ is in fact an alpha-particle nucleus) and the $P_{3 / 2}$ and $P_{1 / 2}$ states are split by the spin-orbit nuclear force, the $P_{1 / 2}$ being at higher energy. The present experiment is similar to the familiar double-scattering experiment except that the first scattering which produces the polarization is replaced by the photodisintegration reaction. Whereas, in the case of double scattering, the polarization is produced by the spin-orbit interaction which depends on the spin orientation, the photodisintegration involves the spin-flipping magnetic dipole and the non-spin-flipping electric dipole transitions. That is, the polarization is produced by an interference between the electromagnetic transitions and we analyze the resulting neutron polarization by a nuclear. scattering.

\section{EXPERIMENTAL DETAILS}

\section{A. Layout of the Experiment}

The experiment was performed by activating a $\mathrm{Na}^{24}$ gamma source in the core of the Livermore Pool-Type Reactor and then transferring it.in a lead container to an experimental setup on the floor of the reactor building. Figures 1 and 2 show the layout of the experiment. The $\mathrm{Na}^{24}$.gamma source was pivoted about the deuterated polyethylene $\left(C D_{2}\right)$ to provide for a range of $\gamma-n$ angles. The $\mathrm{Na}^{24}$ and $\mathrm{CD}_{2}$ were located in a lead cave designed to 


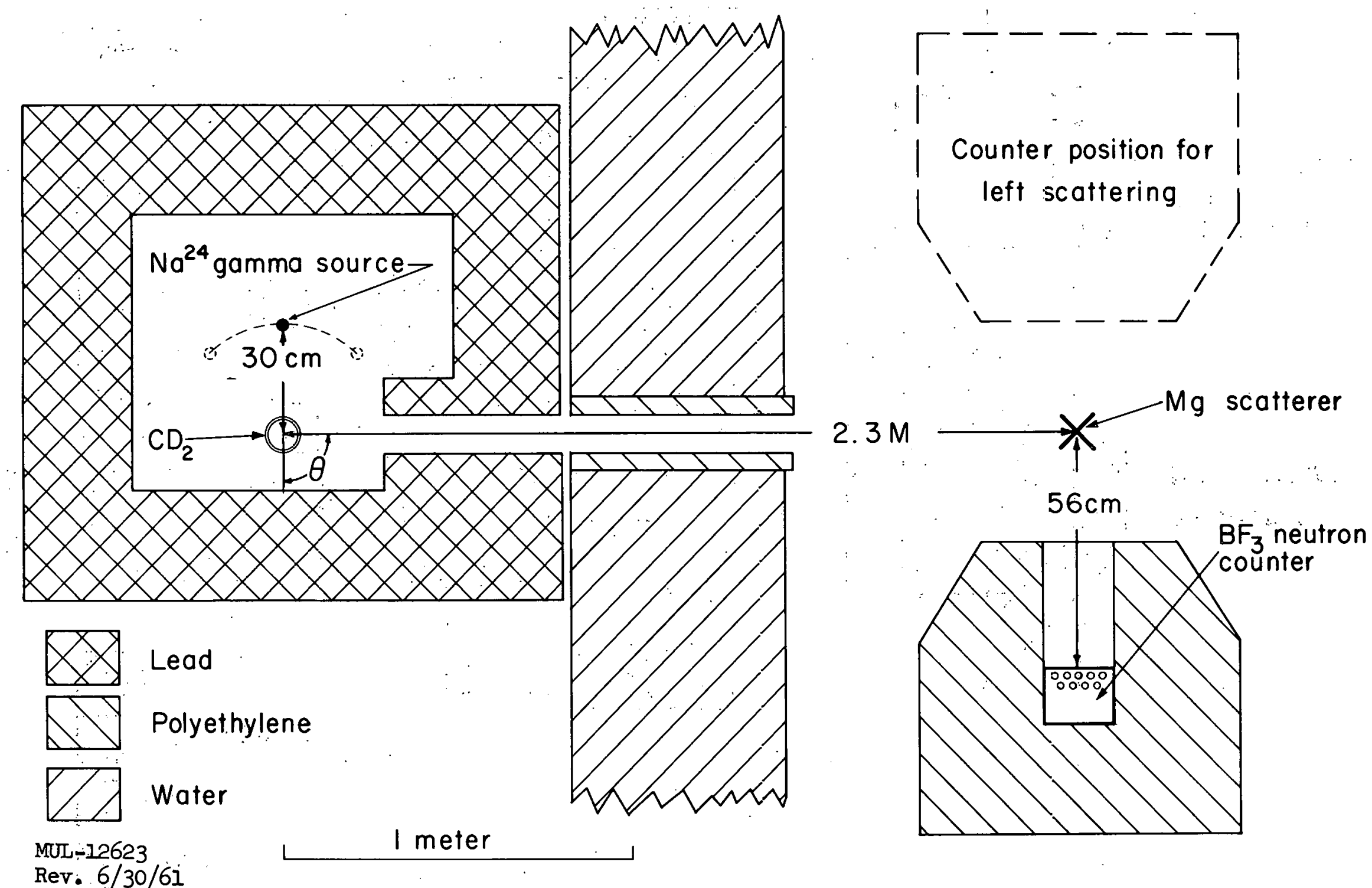

Fig. 1. Plan view of the experimental arrangement. 
$\otimes$ Lead

$\square$ Water

$\triangle$ Polyethylene

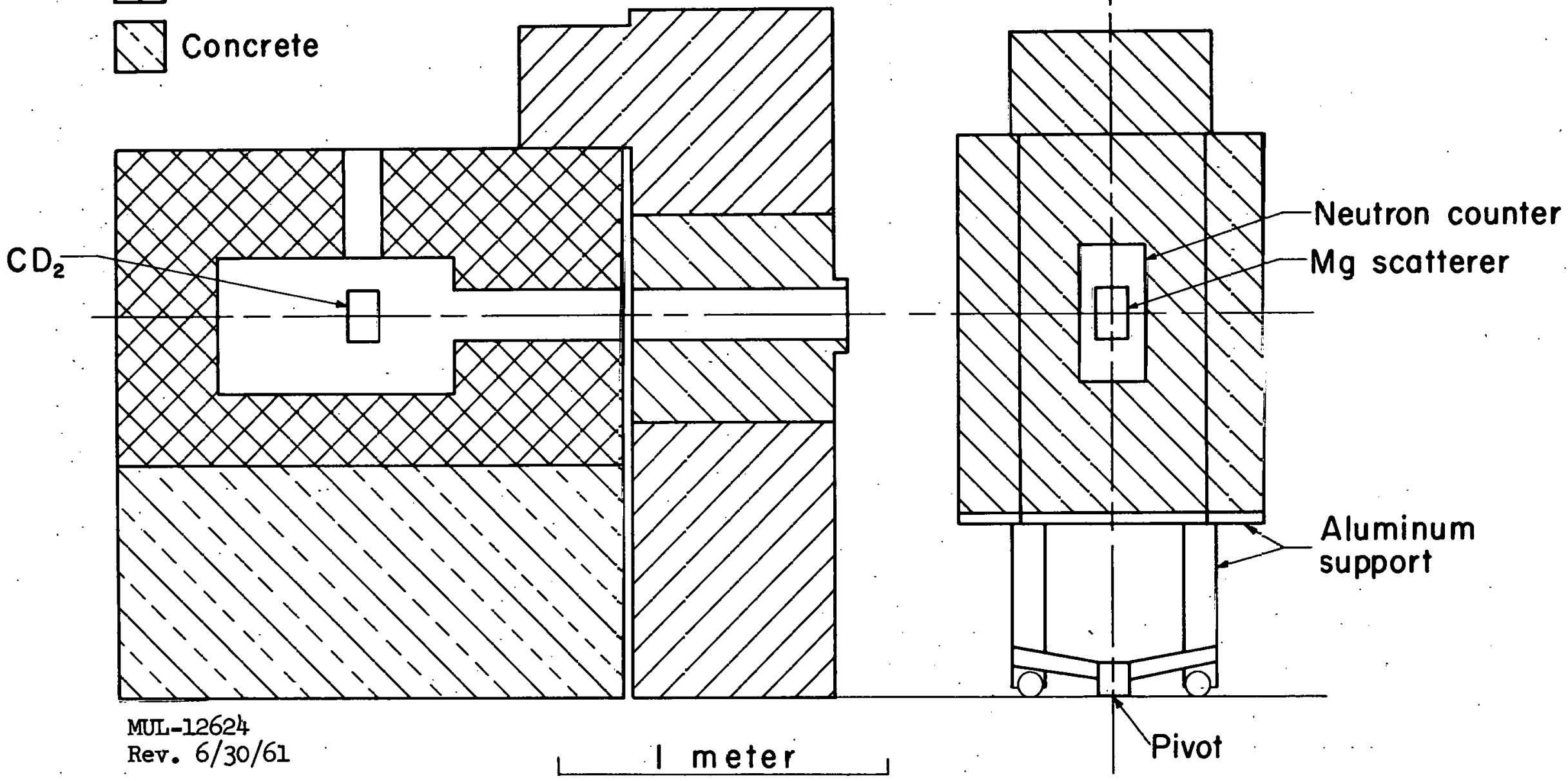

Fig. 2. Side view of the experimental arrangement. 
shield against gamma rays. A water wall placed against one side of the cave shielded the magnesium analyzer and the counter from neutrons. The desired beam of photoneutrons was allowed to emerge from the cave via a collimator in the shielding and to strike the magnesium polarization analyzer.A shielded neutron counter was pivoted about the magnesium to allow counting on the left and right sides of the magnesium.

The major considerations in the design of the experiment were as follows:

1. The scale of the experiment was determined largely by the necessary shielding - about $30 \mathrm{~cm}$ of lead and $60 \mathrm{~cm}$ of water. In addition, the magnesium was located $91 \mathrm{~cm}$ from the water wall to prevent neutrons from travelling from the magnesium to the wall and then scattering into the counter. Thus the $\mathrm{CD}_{2}-\mathrm{Mg}$ distance was over 2 meters.

2. The $\mathrm{Na}^{24}, \mathrm{CD}_{2}$, and $\mathrm{Mg}$ had thickness limitations:

(a) The $\mathrm{Na}^{24}$ source thickness had to be limited to avoid excessive degradation of gamma rays by Compton scattering. Those degraded gamma rays which remained above the photoneutron threshold.would produce neutrons of the wrong energy and of a different degree of polarization.

(b) The $C D_{2}$ thickness was limited to control the amount of neutron scattering within the plastic. Such scattering can change the direction, energy, and polarization of the neutrons.

(c) Finally, the magnesium thickness must be chosen to avoid excessive multiple scattering which reduces the measured left-right ratio.

3. The $\mathrm{Na}^{24}-\mathrm{CD}_{2}$ and $\mathrm{Mg}$ - counter distances were chosen as practical compromises between angular resolution and counting rates. The vertical dimensions of these components were made approximately $50 \%$ greater than horizontal dimensions because the angular resolution is much more dependent on angular spreads in the reaction plane. 


\section{B. Detailed Descriptions of Experimental Components}

1. Lead cave. The inside dimensions were $91-\mathrm{cm} \times 76-\mathrm{cm} \times 41-\mathrm{cm}$ high. Side walls were 30.5-cm thick, made of three widths of lead bricks off set to prevent cracks. A $2.54-\mathrm{cm}$-thick steel plate supported a $30.5-\mathrm{cm}$ lead roof. A $20.3-\mathrm{cm}$ lead floor was supported by $70 \mathrm{~cm}$ of concrete to raise the mid-plane of the reaction to $113 \mathrm{~cm}$ above the floor of the reactor room. The roof contained two $12.7-\mathrm{cm}$ diameter holes. One was used to load the $\mathrm{CD}_{2}$ and the other to load the $\mathrm{Na}^{24}$ source.

The lead served to protect personnel from radiation hazard and also to prevent the generation of photoneutrons from the deuterium contained in the hydrogenous materials of the bulk neutron shielding.

2. Arm for $\mathrm{Na}^{24}$ gamma-source movement. In order to vary the $\gamma-\mathrm{n}$ angle and the $\mathrm{Na}^{24}-\mathrm{CD}_{2}$ distance within the cave, a $40.6-\mathrm{cm}$ aluminum radial arm was constructed with a pivot on the neutron beam axis directly below the $C D_{2}$ neutron source. It was turned by a hand crank which extended up out of the cave through the $\mathrm{CD}_{2}$ loading hole. A small platform was installed on top of the radial arm. The platform was positioned by a long screw driven by a reversible motor. On the platform was a funnel which received and centered the $\mathrm{Na}^{24}$ source from the loading hole at the $90^{\circ}$ position from the $\mathrm{CD} 2$. The funnel was constructed of aluminum with a $1.6-\mathrm{mm}$-thick wall. The $\mathrm{Na}^{24}$ could be positioned from 13.2 to $40.3 \mathrm{~cm}$ from the $\mathrm{CD}_{2}$. Most of the polarization measurements were made at $30.2 \mathrm{~cm}$. The outer end of the rotating arm rolled on two ball bearings. Nine equispaced angles of the arm from $45^{\circ}$ to $135^{\circ}$ were determined by the dropping of the ball bearings into small drilled holes in an aluminum platform under the rotating arm. Figure 3 is a photograph of the inside of the cave; Fig. 4 is an end view. 


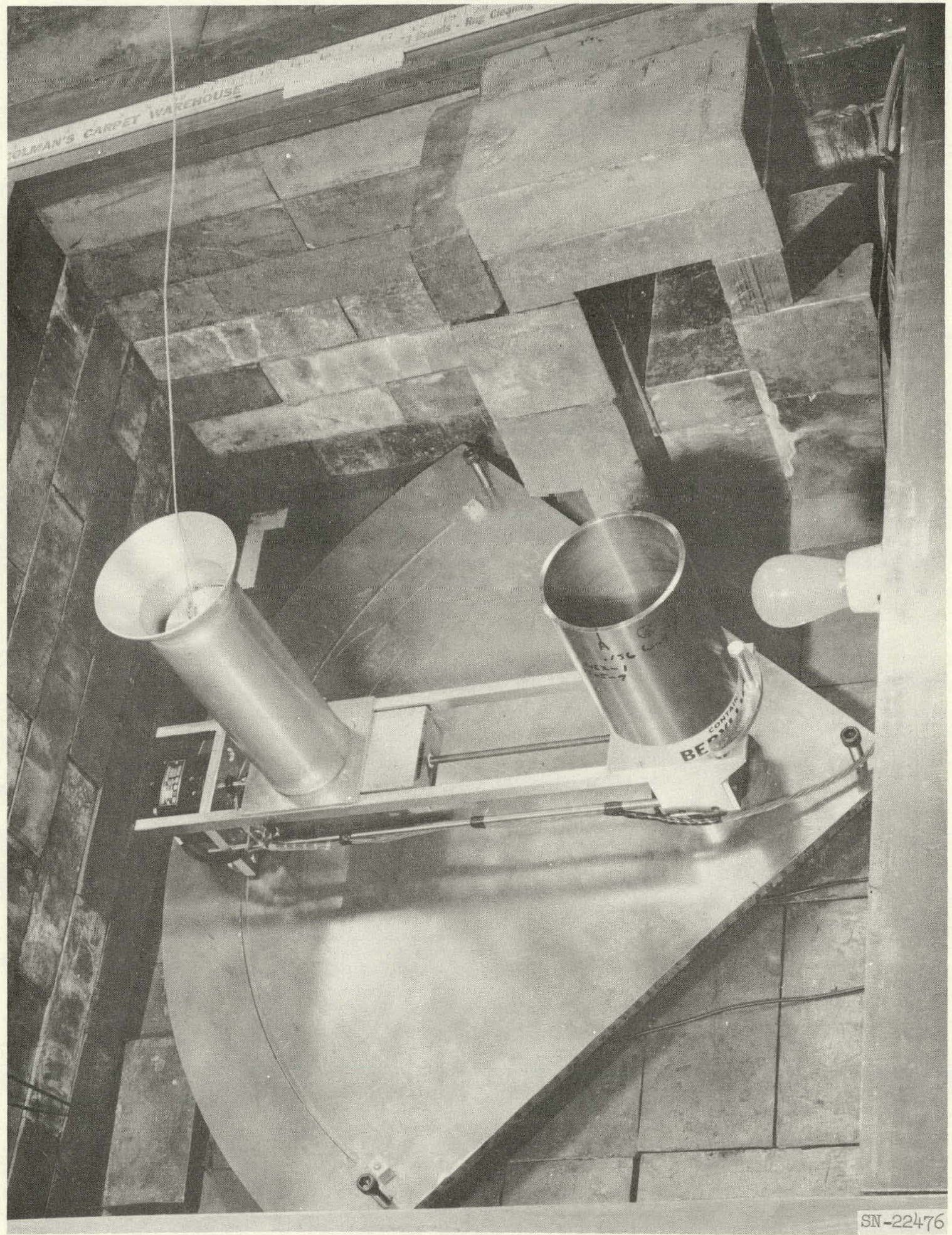

Fig. 3. Photograph showing the inside of the experimental cave. 


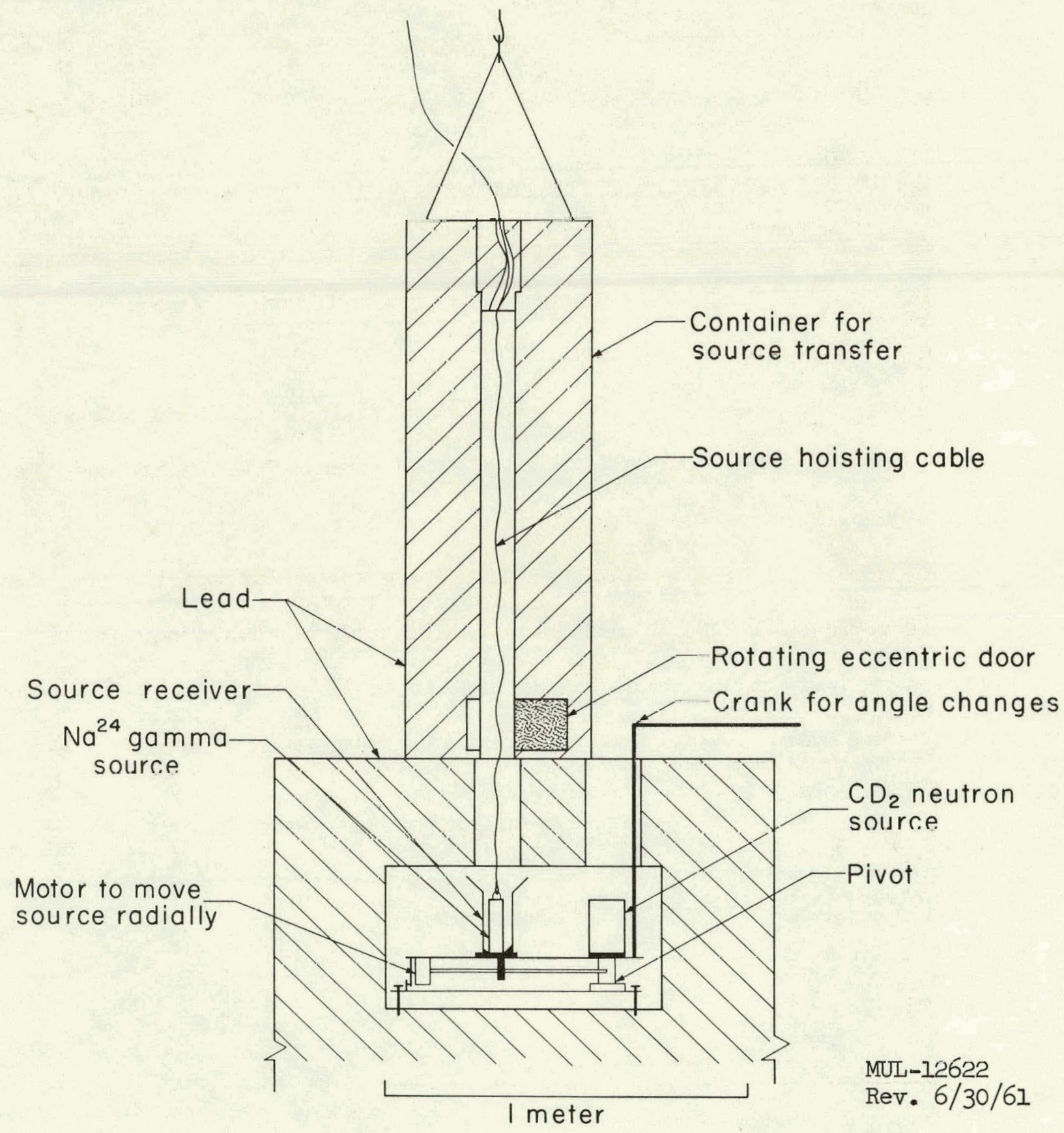

Fig. 4. Detail of the source-handling equipment. 
3. Water wall and collimator. The neutron shielding consisted of $61 \mathrm{~cm}$ of water contained in aluminum tanks. The wall extended 2 meters beyond the sides of the lead cave and $40 \mathrm{~cm}$ above the roof of the cave. The collimator was $10.2-\mathrm{cm}$ wide and $15.2-\mathrm{cm}$ high. The first $45.7 \mathrm{~cm}$ was through lead. The lead collimator was extended $15.2 \mathrm{~cm}$ into the inner cavity of the cave to reduce leakage of gamma rays out of the collimator. The outer $61 \mathrm{~cm}$ of the collimator was constructed of polyethylene fitted between the water tanks.

$$
\text { C. } \mathrm{Na}^{24} \text { Source }
$$

NaF was used as a convenient salt of sodium. Fluorine is a light element producing no long-lived activities. Disks of NaF were cold-pressed under 270.0 atmospheres and stacked in cylindrical aluminum cans. A space $0.16-\mathrm{cm}$ radially and $1.27-\mathrm{cm}$ axially was allowed for possible expansion under activation. The aluminum containers were welded tight against leaks. The cans had a $6.03-\mathrm{cm}$ diameter base to center the source in its position on the radial arm. Actual dimensions of the sources are given in Table I.

Table I. Dimensions of $\mathrm{Na}^{24}$ sources.

\begin{tabular}{ccccccc}
\hline No. & $\begin{array}{c}\text { NaF } \\
\text { height } \\
\mathrm{cm}\end{array}$ & $\begin{array}{c}\text { NaF } \\
\text { diam } \\
\mathrm{cm}\end{array}$ & $\begin{array}{c}\text { Al Wall } \\
\text { Thickness } \\
\mathrm{cm}\end{array}$ & $\begin{array}{c}\text { NaF } \\
\text { wt } \\
\mathrm{g}\end{array}$ & $\begin{array}{c}\text { Al } \\
\text { wt } \\
\mathrm{g}\end{array}$ & $\begin{array}{c}\text { Activity } \\
\text { (curies) }\end{array}$ \\
\hline 1 & 15.2 & 3.18 & 0.32 & 296 & 236 & 530 to 900 \\
2 & 15.2 & 5.72 & 0.32 & 679 & 319 & 1600 \\
\hline
\end{tabular}

A typical sample of the materials used in the sources was activated to a few microcuries and a gamma-ray spectrum made with a NaI spectrometer to test for impurities having gamma rays above $2.225 \mathrm{Mev}$. No appreciable impurities were detected. Also, the decay of the sources was checked during 
the actual runs by taking neutron counts periodically. Over about two halflives, the sources decayed with a 15.0-hour half-life within about $2 \%$.

$$
\text { D. } \mathrm{CD}_{2} \text { Cylinders }
$$

The deuterium neutron sources were molded out of deuterated polyethylene. This makes possible thin, nearly self-supporting sources. The thin $C D_{2}$ cylinder was stiffened by the insertion of three 1 -cm-thick disks of styrofoam. In order to have a reasonable solid angle subtended by the $\mathrm{CD}_{2}$ from the $\mathrm{Na}^{24}$ and at the same time to keep the $C D_{2}$ thin, the $C D_{2}$ was made into a hollow cylinder. The cylinder also preserves the source geometry when the $\gamma-n$ angle is varied. Although one side of the $\mathrm{CD}_{2}$ cylinder is closer to the $\mathrm{Na}^{24}$ than the other, the magnesium scatterer is so far away that this effect is not important.

The cylinders were molded from granular $C D_{2}$ by heating steel molds to $125^{\circ} \mathrm{C}$, then applying 1000 atm pressure to the melted plastic. The inner mold had a slight taper to facilitate removal. Both inner and outer sections of the mold were coated with silicon grease and then lined with aluminum foil prior to loading. After removal of the cylinder from the mold, the aluminum foil was peeled off and the cylinder trued in a lathe. The two finished cylinders had the dimensions listed in Table II.

Table II. Dimensions of $\mathrm{CD}_{2}$ cylinders.

\begin{tabular}{ccccc}
\hline Cyl. & $\begin{array}{c}\text { O.d. } \\
\mathrm{cm}\end{array}$ & $\begin{array}{c}\text { Wall } \\
\mathrm{cm}\end{array}$ & $\begin{array}{c}\text { Weight } \\
\mathrm{g}\end{array}$ & $\begin{array}{c}\text { Height } \\
\mathrm{cm}\end{array}$ \\
\hline thin & 9.68 & 0.152 & 79.4 & 15.40 \\
thick & 9.84 & 0.267 & 137.0 & \\
\hline
\end{tabular}


The hydrogen in the $\mathrm{CD}_{2}$ was more than $99 \%$ deuterium. Since beryllium is the only other element with a photoneutron threshold below $2.75 \mathrm{Mev}$, there was no problem with impurities.

\section{E. Magnesium and Carbon Scatterers}

The scatterers were supported on the collimator axis above the counter pivot point. In order to facilitate rapid changes of scatterer, a light platform consisting of a cross of steel strips was held in place by four piano wires. The wires were attached to the pivot point, to the four corners of the cross, and then flared out slightly to an overhead support well out of the counter's view. A s.tyrofoam disk.was pressed into the cross from the bottom and mechanical stops attached to positively position the scatterers. Total weight of the scatterer platform was approximately $30 \mathrm{grams}$.

A variety of shapes and thicknesses for the scatterers was tried during the experiment. A description of the scatterers is given in Table III. Most of the data were taken with the magnesium thin " $\mathrm{X}$ " and the carbon " $\mathrm{V}$ ". However, the other thicknesses served to give an indication of the multiple scattering effect. The " $\mathrm{X}$ " presents a uniform thickness to the beam and is completely symmetrical to the beam and counter when oriented as shown in Fig. 1. The carbon " $V$ " was placed with the apex on the beam axis and the "V" bisected by the beam axis. The scatterers were designed to cover an area just equal to the cross section of the collimator.

The magnesium metal used for the scatterers had several impurities, the principal ones being $\mathrm{Al}(3 \%) . \mathrm{Zn}(1 \%)$, and $\mathrm{Mn}(0.2 \%)$. A small correction to the data was made for these impurities. 
Table III. Description of magnesium and carbon scatterers.

\begin{tabular}{|c|c|c|c|c|c|}
\hline Material & Shape & $\begin{array}{l}\text { Height } \\
\mathrm{cm}\end{array}$ & $\begin{array}{c}\text { Dimensions } \\
\mathrm{cm}\end{array}$ & $\begin{array}{c}\text { Wall } \\
\text { Thickness } \\
\text { cm }\end{array}$ & $\begin{array}{c}\text { Weight } \\
\text { g }\end{array}$ \\
\hline Magnesium & Thick Cyl. & 15.24 & $10.160 . \mathrm{d}$ & 0.630 & 499.5 \\
\hline$" 1$ & Thin Cyl. & $15.24^{\prime}$ & $10.160 . \mathrm{d}$. & 0.328 & 265.5 \\
\hline$"$. & Thick "X" & 15.24 & $\begin{array}{l}\text { Two plates ea. } \\
15.24 \text { wide.. }\end{array}$ & 0.635 & 469.3 \\
\hline .11 & Thin "X" & 15.24 & $\begin{array}{l}\text { Two plates } \in a . \\
15.24 \text { wide }\end{array}$ & 0.318 & 238.2 \\
\hline iा: & Thin "V" & 15.2 .4 & $\begin{array}{l}\text { Two plates ea. } \\
7.62 \text { wide }\end{array}$ & 0.318 & 119.0 \\
\hline Carbon & Cylindér. & 15.24 & $10.160 . \mathrm{d}$. & 0.508 & 376.1 \\
\hline$"$ & Solid Rod & 15.24 & 4.45 diam & $\ldots$ & 395.7 \\
\hline$" 1$ & "V" & 15.24 & $\begin{array}{l}\text { Two plates ea. } \\
7.62 \text { wide }\end{array}$ & .1 .270 & 450.0 \\
\hline$\therefore$ & & . & & & \\
\hline
\end{tabular}

F. Neutron Counter

Because of the requirements of high efficiency and low gamma-ray sensitivity, a counter consisting of $\mathrm{BF}_{3}$ tubes surrounded by a neutron moderatox was constructed. The inner counter (portion within the thermal neutron shield. ing/ consisted of nine $\mathrm{BF}_{3}$ tubes connected in parallel and embedded in polyethylene $20.3-\mathrm{cm}$ wide by $40.6-\mathrm{cm}$ high by $15.3-\mathrm{cm}$ thick. The $\mathrm{BF}_{3}$ tubes were filled with enriched $\mathrm{BF}_{3}\left(96 \% \mathrm{~B}^{10}\right)$ at $120-\mathrm{cm} \mathrm{Hg}$ pressure. Their arrangement (Fig. 5) was found empirically by tests with the $\mathrm{BF}_{3}$ tubes submerged in a water tank. The tubes were placed near the front face to prevent excessive fall of efficiency at low neutron energies. Over the small range of neutron energies encountered in the present experiment the variation in counter efficiency should be negligible, judging by the performance of other 

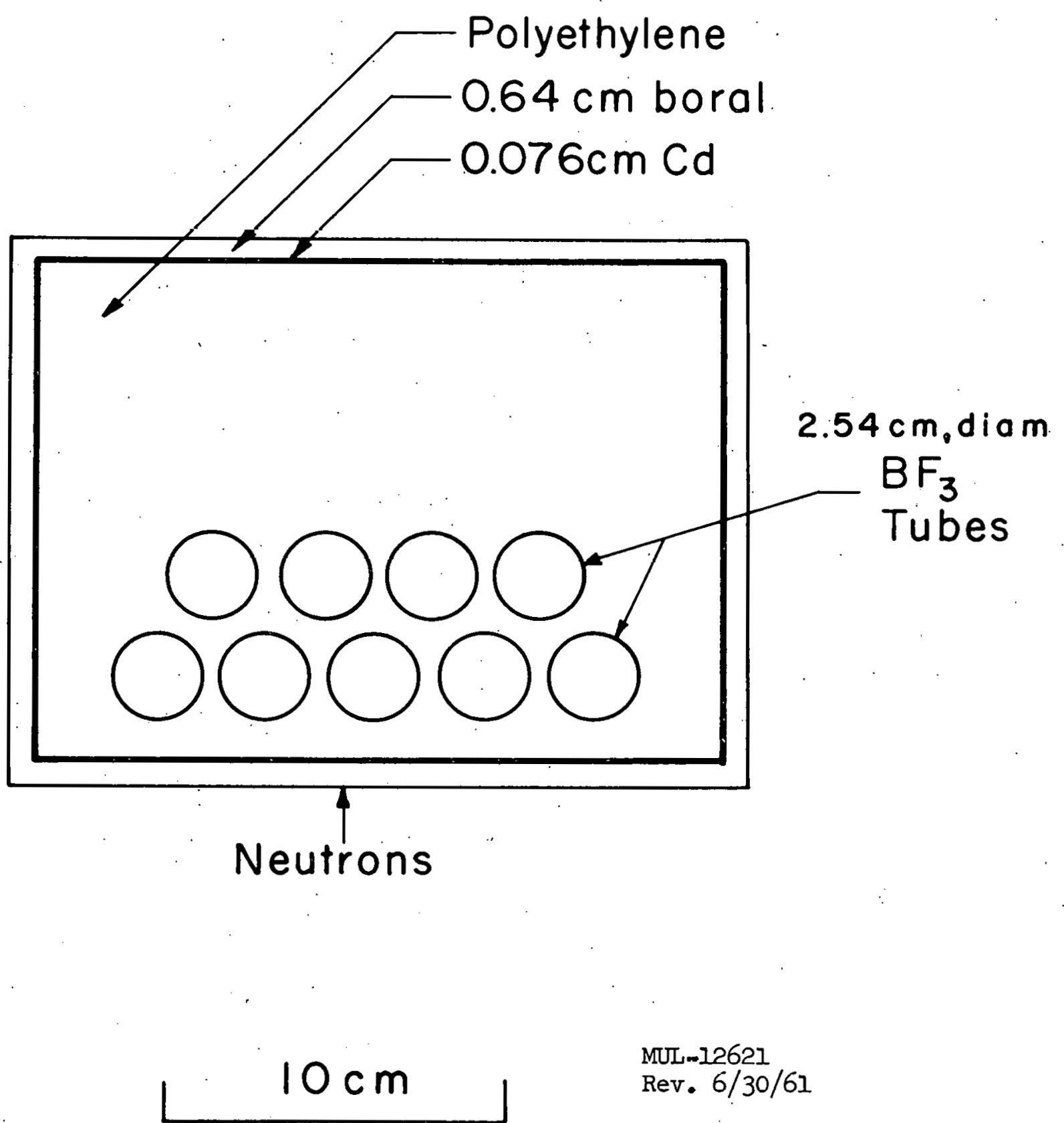

Fig. 5. Top view of the inner neutron counter. 
similar moderated counters. A thermal neutron shield of $0.076 \mathrm{~cm}$ of cadmium and $0.635 \mathrm{~cm}$ of Boral was placed around the inner counter.

The inner counter was surrounded by a massive $(6800-\mathrm{kg})$ laminated shield of polyethylene. A hole in the shield served as a collimator for the inner counter which was recessed $28 \mathrm{~cm}$. The shield serves two purposes, to shield against background neutrons diffusing in the room from all directinns. especially from overhead, and to limit the neutrons scattered from the magnesium to direct paths to the counter, not via surrounding objects.

The entire counter was mounted on a triangular aluminum cart with a bearing for the pivot point and two ball-bearing wheels on the corner legs. The pivot point and wheels were directly on the concrete floor. Positioning of the counter was accomplished by rotating the counter up to mechanical stops on either side of the beam.

The electronics used was standard except for a transistorized preamplifier powered by mercury cells designed by Mr. Howard Spracklen of this Laboratory (see Fig. 6). The $\mathrm{BF}_{3}$ tubes were operated as proportional counters and the scaler discriminator set to cut out almost all gamma-ray counts. Stability of the counter was such that counts taken under the sameconditions were found to be reproducible within the statistics.

\section{EXPERIMENTAL PROCEDURES}

\section{A. Irradiation of $\mathrm{Na}^{24}$ and Source Transfer}

Since $\mathrm{Na}^{24}$ sources in the kilocurie range were required for this experiment, special procedures had to be developed to facilitate safe handling. The $\mathrm{Na}^{24}$ source was attached to a $0.159-\mathrm{cm}$ diameter stainless steel aircraft control cable. This type of cable is flexible, strong, withstands radiation, and does not activate objectionably. For activation, the $\mathrm{Na}^{24}$ was 


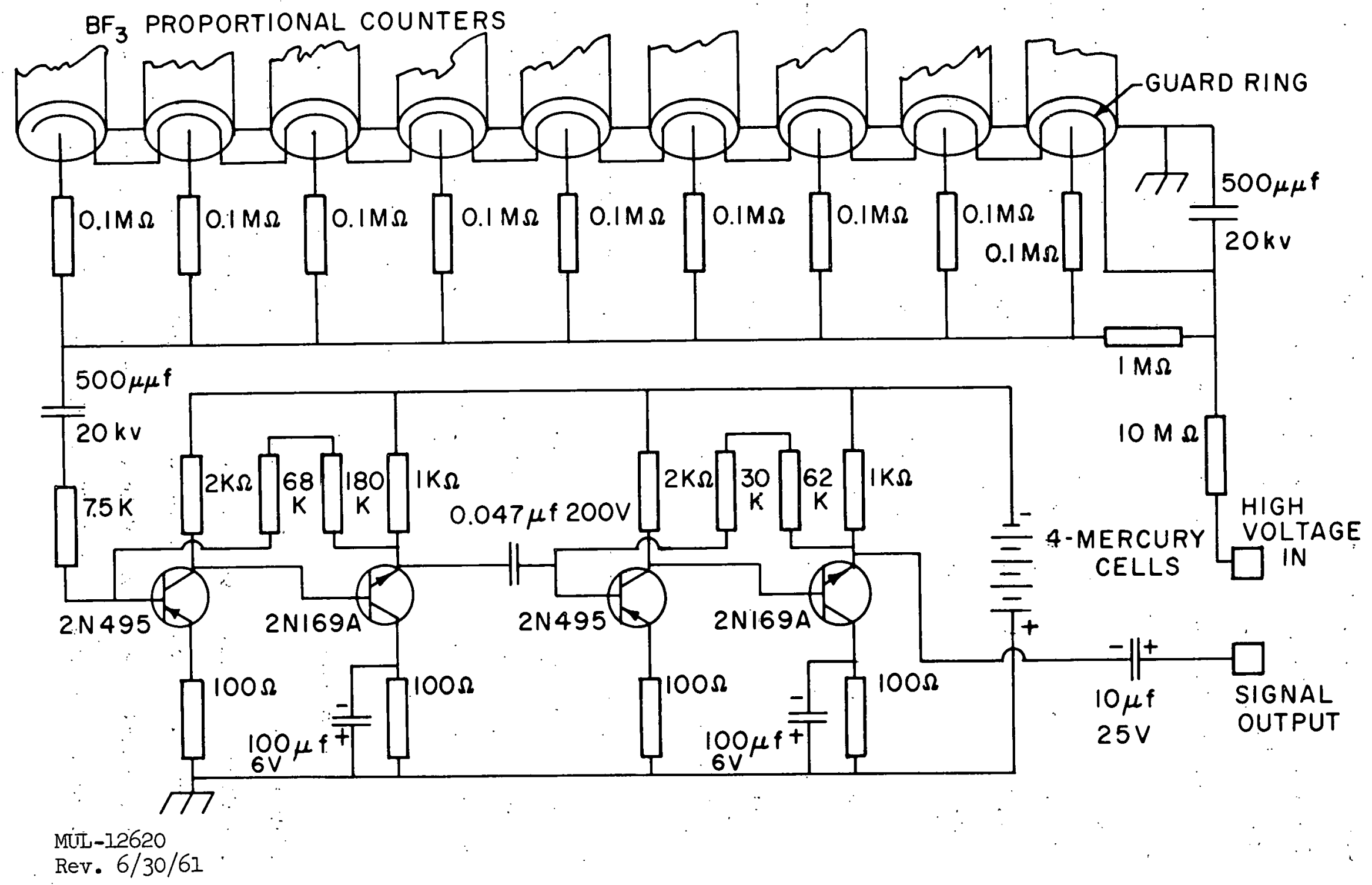

Fig. 6. Transistorized preamplifier for $\mathrm{BF}_{3}$ neutron courter. 
suspended in the center of the core of the reactor in order to obtain maximum flux and uniformity of activation. Typically, the source was exposed to a flux of $5 \times 10^{13}$ neutrons $\mathrm{cm}^{-2} \mathrm{sec}^{-1}$ for 22 hours. After irradiation, the source was loaded into a large, lead, fuel-element coffin. The coffin had 20.3-cmthick walls, was $1.5-\mathrm{m}$ long, and weighed $3180 \mathrm{~kg}$. The top was equipped with a plug with a helical hole which passed the source cable. On the bottom, an eccentric door could be rotated to open the coffin. The coffin was initially submerged in the reactor pool, the bottom door opened, and the source drawn up into the coffin. Then the door was closed and the coffin hoisted by crane clear of the water where it was allowed to drip dry. Afterwards the coffin was lowered onto the experimental cave, the bottom door opened and the source lowered into the funnel on the radial arm. Slack cable allowed movement of the arm within the cave. It was possible to withdraw the source back into the coffin at any time to make changes in the cave. The setup is illustrated in Fig. 4 .

The strongest source (1600 curies) gave a reading of $23 \mathrm{r} / \mathrm{hr}$ on the surface of the coffin. However, by maintaining a reasonable distance and minimizing the time, it was handled safely. No personnel ever received more than the A.E.C. tolerance dose during the experiments.

\section{B. Counting Procedures}

1. Left-right ratio determination. An experiment normally consisted of determining the left-right ratios at from five to nine $\gamma-n$ angles. Since the differential cross section for photodisintegration is peaked at $90^{\circ}$, lower counting rates would be encountered at angles near $45^{\circ}$ or $135^{\circ}$. A fairly steady count rate was maintained by alternating angular positions from the outside angles towards $90^{\circ}$. Thus, the decay of the source was balanced by 
the increase of the differential cross section as $90^{\circ}$ was approached. Typically, ten minute counts were taken in the following order at each angular position:

\begin{tabular}{cll} 
Count & Scatterer & Counter Position \\
\cline { 2 - 2 } 1. & None & Left \\
2. & $\mathrm{Mg}$ & Left \\
3. & $\mathrm{Mg}$ & Right \\
4. & None & Right \\
5. & Carbon & Right \\
6. & Carbon & Left \\
7. & None & Left \\
8. & Mg & Left \\
9. & Mg & Right \\
10. & None & Right
\end{tabular}

After correction for decay, a $\mathrm{Mg} \mathrm{L/R}$ ratio could be calculated. For example:

$$
\frac{L}{\mathrm{R}}=\frac{\operatorname{count} 2-\operatorname{count} 1}{\operatorname{count} 3-\operatorname{count} 4}
$$

Typical counting rates with thin $\mathrm{CD}_{2}$ and thin $\mathrm{Mg}$ "X". were $1000 \mathrm{cpm}$, with no-scatterer rates $50 \%$ to $60 \%$ as high. No-scatterer counts taken with the collimator plugged with polyethylene showed that approximately $70 \%$ of the counting rate was due to neutrons which did not come through the collimator. Most of these probably came over the top of the water wall by air scattering.

The experiment to measure the left-right ratio was performed four times, each run lasting about 30 hours or two half-lives of the source.' The conditions for the runs are summarized in Table IV. 
Table IV. Summary of experimental runs.

\begin{tabular}{|c|c|c|c|c|c|c|c|c|c|c|c|c|c|c|c|}
\hline \multirow[b]{3}{*}{ Run No. } & \multirow[b]{3}{*}{$\begin{array}{l}\text { Source No. } \\
\text { (See Table 1) }\end{array}$} & \multirow{3}{*}{$\begin{array}{l}\mathrm{Na}^{24} \\
\text { Strength } \\
\text { (curies) }\end{array}$} & \multirow{3}{*}{$\begin{array}{l}\mathrm{CD}_{2} \\
\mathrm{Cyl} . \\
\text { (See } \\
\text { Tajole } \\
\text { II) }\end{array}$} & \multicolumn{8}{|c|}{ Scatterers and Shape: (See Table III) } & & & & \\
\hline & & & & \multicolumn{5}{|c|}{ Magnesium } & \multicolumn{3}{|c|}{ Carbon } & \multicolumn{4}{|c|}{ Neasurements } \\
\hline & & & & $\begin{array}{l}\text { Thick } \\
\text { Cyi. }\end{array}$ & $\begin{array}{l}\text { Thin } \\
\text { Cyl. }\end{array}$ & Thick & $\begin{array}{l}\text { Thin } \\
\text { "X" }\end{array}$ & $\begin{array}{l}\text { Thin } \\
\text { "V" }\end{array}$ & Cyl. & Rod & 'V' & $\begin{array}{c}\mathrm{L} / \mathrm{R} \\
\text { Ratio }\end{array}$ & $\begin{array}{l}\text { Of: Cente } \\
\text { Ba:kgrou: }\end{array}$ & $\begin{array}{l}\text { er } \\
\text { and }\end{array}$ & $\begin{array}{c}\text { Angular } \\
\text { Distribution }\end{array}$ \\
\hline 1 & 1 & 50 & Thin & & & & & & & & & & & & $\mathrm{x}$ \\
\hline \multirow[t]{2}{*}{2} & 1 & 530 & Thin & $\mathrm{x}$ & & & & & $\mathrm{x}$ & & & $5 / s$ & $\mathrm{x}$ & & \\
\hline & & . & Thin & & $\mathrm{x}$ & & & & . & & & $90^{\circ}$ & & & : \\
\hline \multirow[t]{2}{*}{3} & 1 & 733 & Thin & & & $\mathbf{x}$ & $\mathbf{x}$ & & & & $x$ & $5 / 8$ & $\dot{\mathrm{x}}$ & . & . \\
\hline & & & Thin & & & & $\cdot$ & & & $\mathbf{x}$ & $\mathrm{x}$ & $90^{\circ}$ & & & \\
\hline \multirow[t]{2}{*}{4} & י. & 1600 & Thin & . & & & $x$ & & & & $\mathrm{x}$ & $9 / \mathrm{s}$ & & & \\
\hline & & & Thick & & & & & $\mathrm{x}$. & & & $x$ & $90^{\circ}$ & & & \\
\hline \multirow[t]{2}{*}{5} & 1 & 900 & Thin & & & & $\mathrm{x}$ & & & & $x$ & $9 / 8$ & & & \\
\hline & & & Thick & & & $x$ & & & & & $x$ & $5 / 8$ & & : & 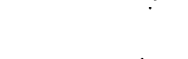 \\
\hline
\end{tabular}


2. "Off-center" counts. Neutrons from the $C D_{2}$ could scatter from the inner walls of the cave (especially the back wall) and eventually emerge from the collimator. In order to derive an empirical correction for this source of background, the $C D_{2}$ was displaced $20.2 \mathrm{~cm}$ on the radial.arm so that neutrons could not leave through the collimator directly.. The $\mathrm{Na}^{24}$ source was also displaced, the counts being corrected to the usual $\mathrm{Na}-\mathrm{CD}_{2}$ separation. Counts were taken at several angles, the procedure being the same as outlined in paragraph 1 above for normal counts. The resulting "off-center" counts were subtracted from the corresponding normal counts as a background. The "off-center" background was $8 \%$ of the normal count at $90^{\circ}$. It was fairly constant in absolute value for all angles, as one would expect for neutrons randomly scattered.

3. Angular distribution measurement. The angular distribution of the photoneutrons from the $\mathrm{CD}_{2}$ was measured by rotating the counter into the direct beam from the collimator. The $\mathrm{Na}^{24}-\mathrm{CD}_{2}$ distance was $40.3 \mathrm{~cm}$. Counts were taken for the nine angles normally available on the arm. Then the measurements were extended to forward angles by displacing the $\mathrm{CD}_{2}$ along the collimator axis towards the magnesium. Several angles were set up by a combination of angular and radial displacements of the $\mathrm{Na}^{24}$. Similarly, backward angles were reached by displacing the $C D_{2}$ along the collimator axis away from the magnesium. "Off-center" counts were taken with the $C D_{2}$ displaced out of the direct acceptance of the collimator and subtracted as a background: All counts were corrected to a common time. Statistics were $1 \%$ or better. The resulting angular distribution is plotted in Fig. 7.

\section{Experimental Tests and Checks}

1. Gamma-ray background. A count was taken with the $\mathrm{Na}^{24}$ in place but no $C D_{2}$ in the cave. The result, $15 \mathrm{cpm}$, indicated that the counter was 


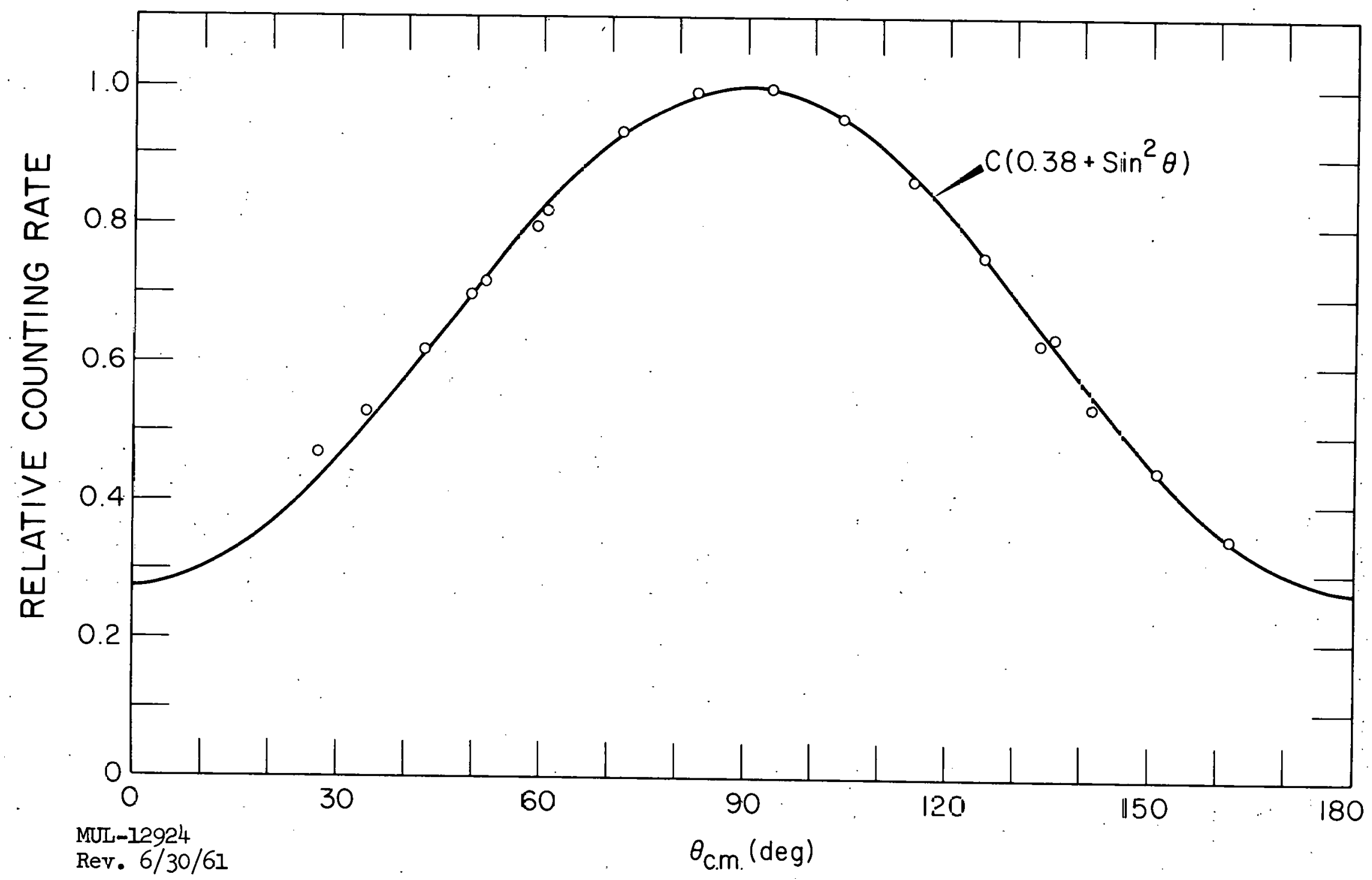

Fig. 7. Angular distribution of $\mathrm{Na}^{24}-\mathrm{D}$ photoneutrons. 
not sensitive to gamma rays and that neutrons were not generated outside of the $C D_{2}$. The gamma radiation level on the face of the counter was approximately $1 \mathrm{mr} \mathrm{hr}$.

2. Carbon scatterer. The most conclusive test for built-in asymmetries in the experimental setup consisted of replacing the magnesium.scatterer by carbon. Carbon has no resonances in this energy region and has been found by other observers ${ }^{18,21}$ to give no left-right asymmetry in the scattering of polarized neutrons. As indicated above, the carbon runs were alternated with the magnesium runs. No significant asymmetries were found with the carbon。

3. Beryllium neutron source. For one measurement, the $\mathrm{CD}_{2}$ was replaced by a beryllium cylinder $(15.24-\mathrm{cm}$ high, $10.16-\mathrm{cm} \mathrm{o.d.,} 0.40-\mathrm{cm}$ -thick, weighing $348.7 \mathrm{~g})$ and the left-right ratio determined for the beryllium photoneutrons at $90^{\circ}$. The left-right ratio for the thick magnesium "X". scatterer was $0.91 \pm 0.14 . \mathrm{Na}^{24}-\mathrm{Be}$ photoneutrons at $90^{\circ}$ have nearly $1-\mathrm{Mev}$ energy. Since the polarization is not known from theory and the analyzing properties of magnesium at this energy are also unknown, the measured left right ratio is not significant except that it is different from that found with the $\mathrm{Na}^{24}-\mathrm{CD}_{2}$ neutrons, as one would in general expect if the effect of the 260 -kev magnesium resonance is specific to the deuterium neutrons.

4. Collimator shape. Some neutrons from the $\mathrm{CD}_{2}$ : are scattered by the walls of the collimator. This may change the polarization and the energy of those neutrons. In order to investigate this effect experimentally, we changed the shape of the collimator and looked for changes in the measured left-right ratio. In one trial, the collimator was reduced to $5.1-\mathrm{cm}$ wide and 12.7-cm high by inserting more polyethylene in the polyethylene end of the collimator. In another trial, the collimator was reduced to $10.2-\mathrm{cm}$ wide and 
$7.6-\mathrm{cm}$ high. In neither trial was any statistically significant change in the left-right ratio noted. Thus, despite the relatively crude collimator used, scattering from the collimator was apparently not important. Some factors which tend to suppress this effect are: the fact that the magnesium scattering cross section for neutrons with degraded energy is smaller than for unscat tered neutrons; that some of the scattered neutrons fan out and miss the magnesium scatterer which covers only the area of the collimator; and; finally, neutrons scattered through small angles may not lose their polarization. On the other hand, a more refined collimator design might be desirable in a future experiment.

5. Counter tests. To investigate possible effects associated with very low energy neutrons, a left-right ratio was measured with $0.96 \mathrm{~cm}$ of Lucite absorber on the face of the counter. The counting rate was reduced by $23 \%$ but the usual left-right asymmetry was observed.

The polarization-scattering of magnesium varies fairly slowly with the scattering angle judging by the measurements by the Argonne Group 18 at $90^{\circ}$ and $45^{\circ}$. In addition, the vertical extent of the counter should have only a small effect on the asymmetry. However, we made one asymmetry measurement with the counter aperture reduced to $20.3 \mathrm{~cm}$ by $19.1 \mathrm{~cm}$. No significant change in the left-right ratio was noted.

\section{RESULTS}

\section{A. 'Left-Right Ratios and Polarization}

The counts from Runs 3 and 5 were combined for the five angles common to both runs. The results were corrected for "off-center" background only. Those ratios are listed in Table V, and plotted in Fig. 8. The errors shown are statistical only. 
Táble V. Measured left-right ratios and calculated photoneutron polarization.

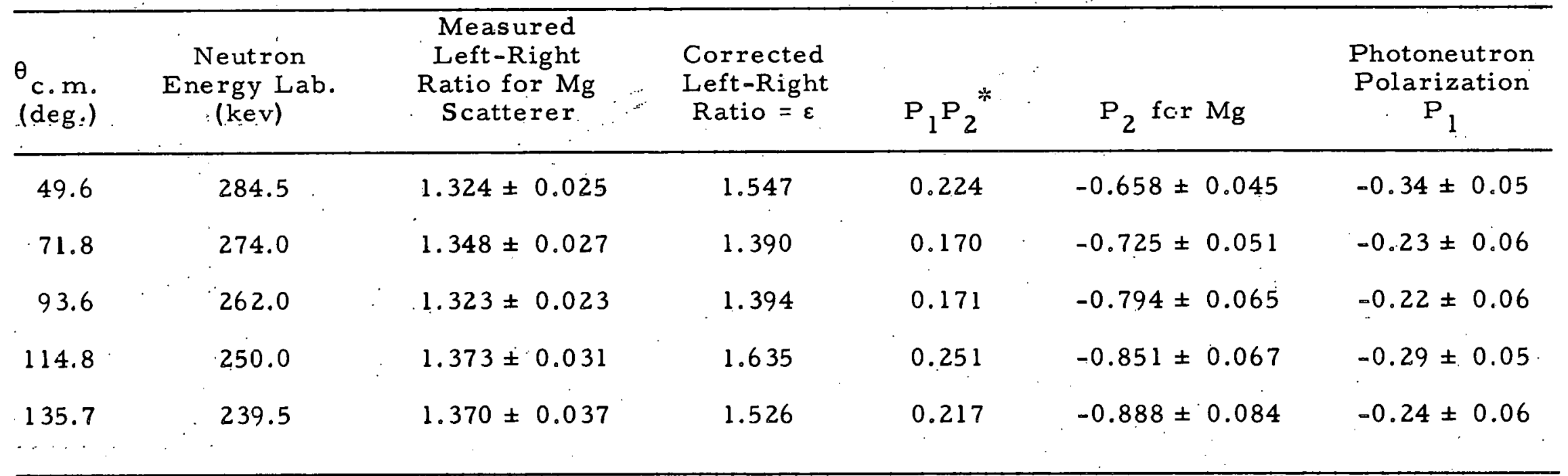

${ }^{*} \mathrm{P}_{1} \mathrm{P}_{2}=\frac{1}{0.96} \times \frac{\varepsilon-1}{\varepsilon+1}$ where $0.96=\overline{\left[\frac{\overrightarrow{\mathrm{P}}_{1} \cdot \overrightarrow{\mathrm{P}}_{2}}{\left|\mathrm{P}_{1} \mathrm{P}_{2}\right|}\right]}$ 


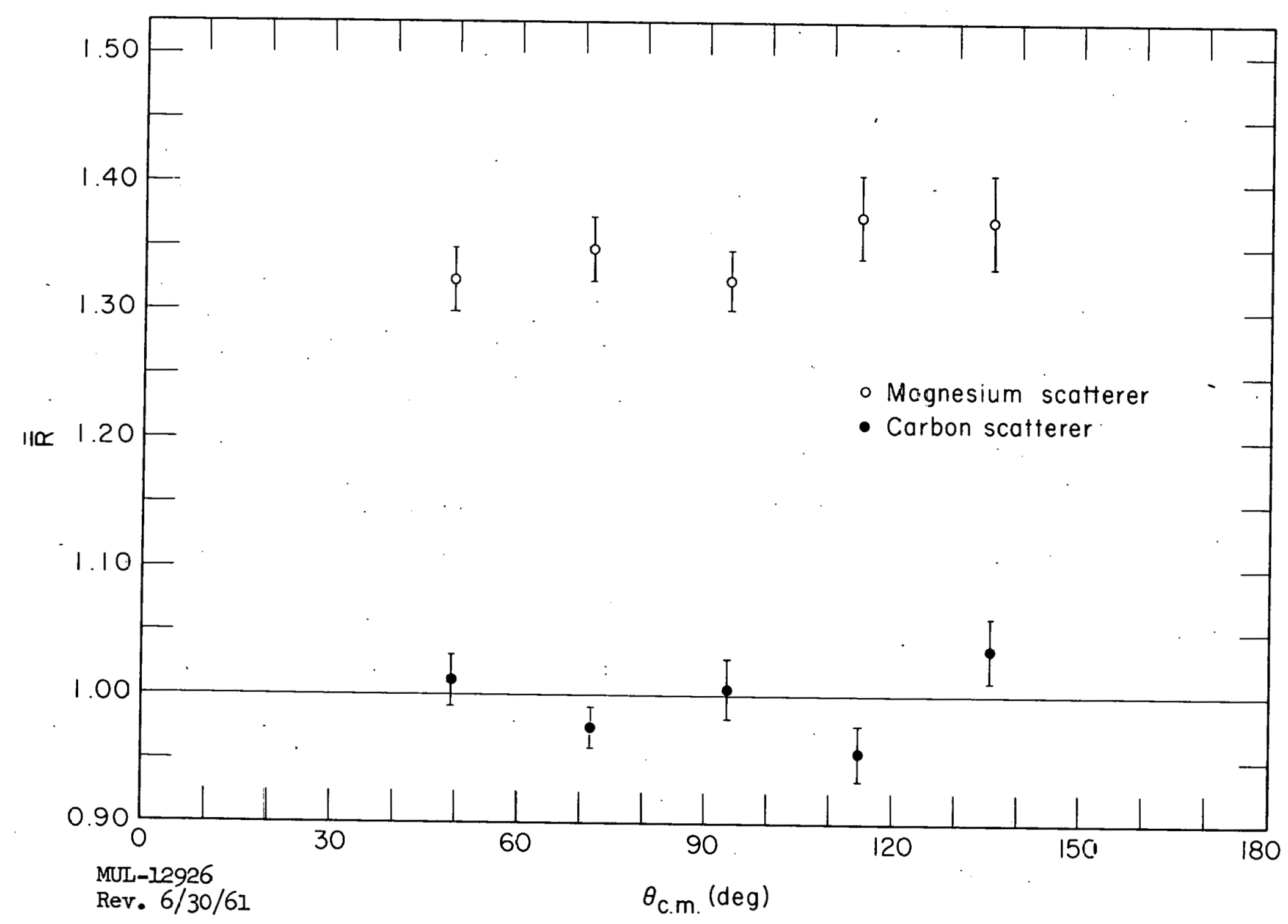

Fig. 8. Measured left-right ratios. Errors shown are statistical only. 
The left-right ratios were then corrected for several effects which reduce the observed ratio from the true ratio. "These corrections are dis cussed in detail in Section VII. From the corrected left-right ratio, $\varepsilon$, we calculated $\mathrm{P}_{1} \mathrm{P}_{2}$, the product of the polarization, $\mathrm{P}_{1}$, of the incident beam by the polarization, $P_{2}$, for the scattering from magnesium, using the following relation:

$$
P_{1} P_{2}=(1 / 0.96)[(\varepsilon-1) /(\varepsilon+1)]:
$$

where 0.96 is the average cosine of the angle between the reaction and scattering planes arising from the finite extent of the sources and counter. $\mathrm{P}_{2}$, the polarization for scattering by magnesium, was taken from the work of Elwyn, Lane, and Langsdorf ${ }^{18}$ and listed in Table V. The errors shown were quoted by them. The sign convention used here is that the polarization is positive for a net spin orientation in the direction of the vector $\vec{k}_{i} \times \vec{k}_{f}$ where the $k^{\prime} s$ are the wave numbers of the incident and final produced particles. Finally, $P_{1}$ was calculated from $P_{1} P_{2}$ and $P_{2}$. The error in $P_{1}$ includes the major known uncertainties as explained in Section VII.

Figure 9 is a plot of $P_{1}$. The curve shown is a plot of the theoretical curve derived by Kramer. ${ }^{10}$ Kramer's calculation, carried out for $\mathrm{E}_{\gamma}=$ 2.759 Mev, depends on two parameters, the singlet scattering length, and the singlet range. The singlet scattering length is experimentally known; 22 $a_{s}=-23.69 \pm 0.055 \times 10^{-13} \mathrm{~cm}$. On the other hand, the singlet $\mathrm{range}$ is not well known. Kramer's results for three values of the singlet range are given below, where $\gamma_{0}$ is the parameter in the expression for the polarization given in Section II, $a$ and $b$ are the coefficients of the angular distribution, and $\sigma_{T}$ is the total cross section for photodisintegration. 


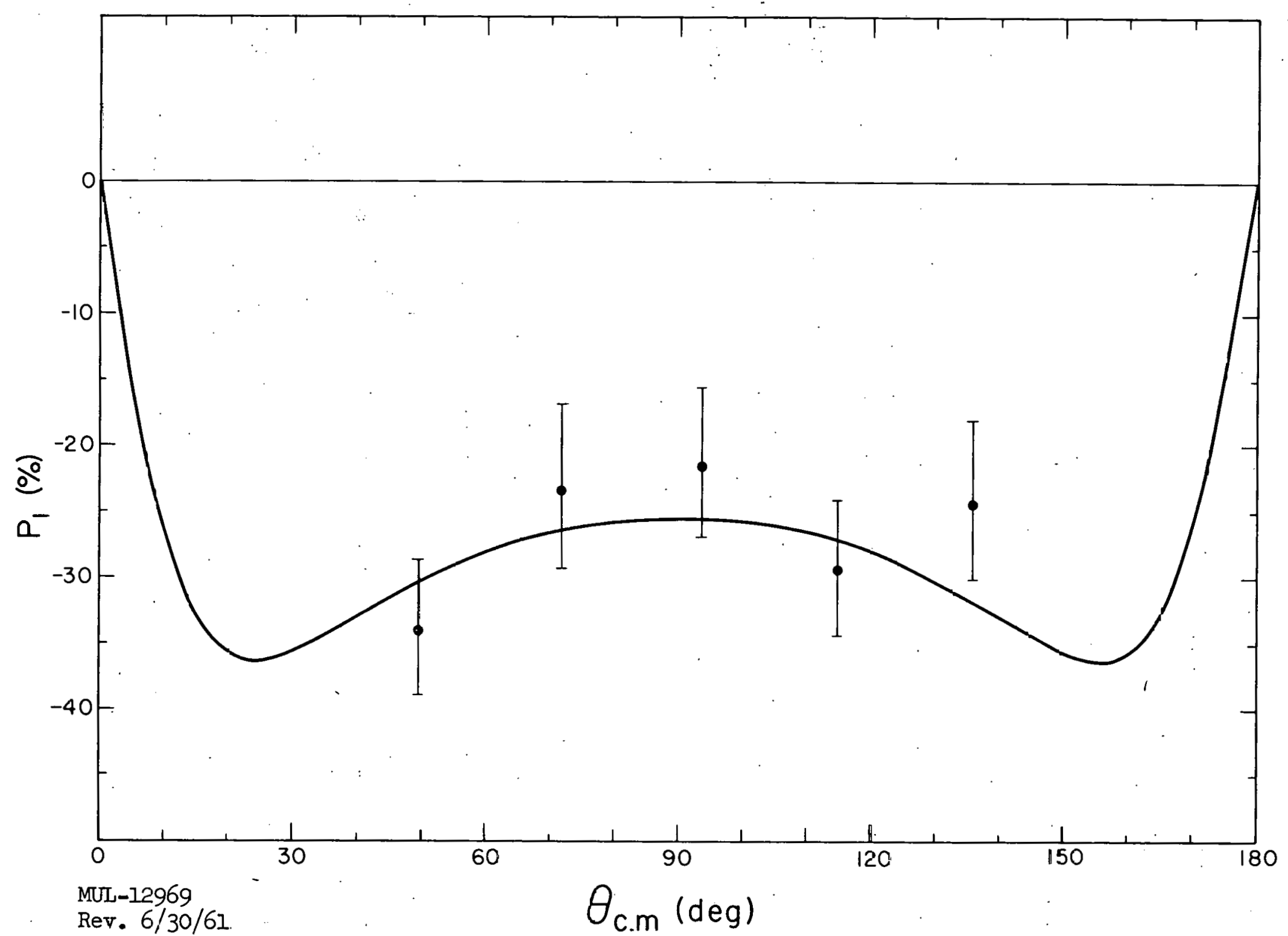

Fig. 9. Polarization of the neutrons from the reaction $\mathrm{D}(\gamma, \mathrm{n}) \mathrm{H}$. The errors shown inslude the statistical errors from this experiment and the uncertainty in $P_{2}$ for magnesium. The theoretical curve is from the calculation by $\mathrm{G}$. Kramer. 


\begin{tabular}{|c|c|c|c|c|c|c|}
\hline & $\begin{array}{c}\text { Singlet Range } \\
\times 10^{-13} \mathrm{~cm}\end{array}$ & $\gamma_{0}(\mu b)$ & $a(\mu b)$ & $b(\mu b)$ & $\ldots \quad a / b$ & $\sigma_{T}(\mu b)$ \\
\hline & 2.0 & -41.2 & $23: 8$ & 136.9 & $\because 0.174$ & $\because 1446$ \\
\hline & 2.4 & -40.9 & 23.0 & 136.9 & 0.168 & $: 1436$ \\
\hline & 2.8 & -40.3 & 22.0 & 136.9 & 0.161 & 1423 \\
\hline
\end{tabular}

We have chosen case 2 above since the $a / b$ is fairly close to the experimental value. 23 We note that $\gamma_{0}$ is not very sensitive to the assumed value of the singlet range. It should be pointed out that $\sigma_{T}$ for all three cases is lower than experimental values by about $4 \%$, although the quoted experimental errors are nearly large enough to overlap the theoretical value.

\section{B. Angular Distribution}

The measured angular distribution for the $\mathrm{Na}^{24}-\mathrm{D}$ neutrons from our source is plotted in Fig. 7, togethe $r$ with a curve which was fitted to the data. The angular distribution was useful mainly as a check on the scattering of the neutrons in the $C D_{2}$. This is discussed in Section VII.

\section{CORRECTIONS AND UNCERTAINTIES}

A. Compton Scattering in the $\mathrm{Na}^{24}$ Source

Compton scattering of the gamma rays degrades the gamma-ray energy. One finds from the kinematics of Compton scattering that after scattering through an angle of $17^{\circ}$ or greater, a $2.753-\mathrm{Mev}$ gamma ray has an energy below $2.225 \mathrm{Mev}$, the photodisintegration threshold. This fact shows that those gamma rays which have been scattered by the inner walls of the cave cannot produce photoneutrons. However, some gammas are scattered in the source itself and in the surrounding aluminum funnel. 
For Source No. 1, using the total Compton-scattering cross section, we find that $14.4 \%$ of the gamma rays are Compton-scattered in the source and funnel. From the differential cross section for Compton scattering we estimate from a rough numerical integration that, of those gammas which are scattered, $16 \%$ are scattered through an angle of $17^{\circ}$ or less. The scattered gammas which are above the photodisintegration threshold therefore constitute $(0.16)(14.4 \%)=2.3 \%$ of the total. Since the source possesses cylindrical symmetry, the angular distribution of scattered as well as unscattered gammas is isotropic in azimuth. Photoneutrons produced by the degraded $2.3 \%$ of the gammas will have the wrong energy for the magnesium resonance scattering and will be scattered with little left-right asymmetry, except that those neutrons with energies near the $83-k e v$ resonance will probably be scattered with the opposite asymmetry. For the purpose of correcting the experimental data, we assume that $2.3 \%$ of the gammas produce unpolarized neutrons. This means that the measured left-right ratio was low by about $1 \%$ from Compton scattering.

Experimentally, Run 4 with Source 2 (approximately twice as thick as Source 1) gave an average left-right ratio, over nine angles, of 1.268. The corresponding average for Run 5 with Source 1 was 1.304 . On the other hand, Run 3 with Source 1 gave an average of 1.331 for 5 angles. Thus, any possible source thickness effect is obscured by statistical fluctuations and reproducibility difficultics.

A test with $5 \mathrm{~cm}$ of aluminum absorber placed between the $\mathrm{Na}^{24}$ and $C D_{2}$ failed to show any appreciable change in the left-right ratio.

B. Neutron Scattering in the $\mathrm{CD}_{2}$ :

A certain fraction of the photoneutrons may be scattered within the $C D_{2}$. undergoing possible changes in direction, energy, and polarization. We 
considered this effect too complicated to calculate, therefore, an empirical correction was derived from the measurements with two $C D_{2}$ cylinders having wall thicknesses of $0.152 \mathrm{~cm}$ and $0.267 \mathrm{~cm}$. The correction was based on a linear extrapolation (of the left-right ratio) to zero $\mathrm{CD}_{2}$ thickness. This procedure was applied to the data for each of the five angles. The resulting corrections correspond to a fraction of neutrons scattered (and depolarized) equal to $21 \%$, when averaged over the 5 angles. This correction is the largest of the experiment and furthermore affects the angular dependence of the polarization. The correction depends on two asymmetry measurements which results in an increased uncertainty, due to statistics, in the corrected.leftright ratio.

The angular distribution of Fig. 7. can be used to give an independent estimate of the $C D_{2}$ scattering. A previous accurate measurement of the angular distribution for a $\mathrm{Na}^{24}-\mathrm{D}$ source based on counting photo protons in deuterium gas gave the result ${ }^{23}$ :

$$
\mathrm{d} \sigma / \mathrm{d} \Omega=C\left(0.167+\sin ^{2} \theta\right)
$$

Our angular distribution was fitted by the curve

$$
\mathrm{d} \sigma / \mathrm{d} \Omega=\mathrm{K}\left(0.38+\sin ^{2} \theta\right)
$$

If one assumes that in our case a fraction $f$ of the total flux of neutrons was scattered isotropically, then, from the above angular distributions, it follows that $f=21 \%$. This isotropic scattered component. (assumed unpolarized) results in a $16 \%$ unpolarized component at $90^{\circ}$ and $33 \%$ at $45^{\circ}$, the factor of 2 arising from the change in differential cross section. Thus, the correction is expected to produce a curvature in the calculated polarization which is convex upward as plotted in Fig. 9. The correction derived here was found to be in surprising agreement, with the empirical correction from the sourcethickness extrapolation. However, we have not considered how the magnesium 
scatterer modifies the effect. The modification depends on the energy spectrum of the scattered neutrons and the magnesium cross section variation with energy. Therefore we can only consider the angular distribution as qualitative evidence for the correction.

\section{Midnesium impiritifis}

The abundances of the magnesium impurities (see Section IV, E) were weighted by their respective average neutron-scattering cross sections in the energy range of this experiment. These weighted abundances were divided by the weighted abundances for all constituents, including the magnesium. Assuming that the impurities have no scattering asymmetry, the result is equivalent to $1.6 \%$ of the neutrons being scattered without asymmetry. The effect on the left-right ratio is about $0.8 \%$.

\section{Finite Geometry}

From the left-right ratio, one calculates $\mathrm{P}_{1} \mathrm{P}_{2} \cos \psi$, where $\psi$ is the angle between $\vec{P}_{1}$ and $\vec{P}_{2}$, or, in other words, the angle between the photoproduction and $\mathrm{Mg}$ scattering planes. We have calculated an average cos $\psi$ considering only the vertical dimensions of the $\mathrm{Na}^{24}, \mathrm{CD}_{2}, \mathrm{Mg}$, and counter. Using this rough approximation, it is possible to carry out the resulting integrals analytically. The result is $\cos \psi=0.96$ 。

\section{E. Multiple Scattering in Magnesium}

It is difficult to calculate the multiple scattering correction, including polarization effects and nonisotropic angular distributions. In fact, we do not at present have adequate data on the angular distribution for this purpose. The Argonne group ${ }^{18}$ has investigated the multiple scattering experimentally by measuring the left-right ratios for scattering of polarized neutrons from 
various thicknesses of $\mathrm{Mg}$. They find a trend towards higher left-right ratios in going down to a thickness of $3.2 \mathrm{~mm}$ (a single slab at $45^{\circ}$ to the beam), but for smaller thicknesses the trend was not clear, the changes of asymmetry with thickness being of the order of the statistical uncertainties. The Argonne data were taken with thicknesses of $3.2 \mathrm{~mm}$ or less, and no correction for multiple scattering was applied.

Our own measurements of asymmetry vs $\mathrm{Mg}$ thickness were qualitatively in agreement with the Argonne results. We also have not applied any multiple scattering to the data. Fortunately, the correction is canceled if it is applied to both the Argonne data and to our data for equal Mg thicknesses. Our data were taken with two $3.2-\mathrm{mm}$ slabs forming a cross. We estimate that such a.cross is about $60 \%$ thicker than a single $3.2-\mathrm{mm}$ slab for multiple scattering purposes. Thus, a small multiple-scattering effect remains, but we consider that less uncertainty is involved if we do not attempt a correction.

\section{F。 Errors}

The corrections described above were applied to the data. Mechanical asymmetries in the apparatus are believed to affect the left-right ratio by less than $1 \%$. The carbon results can be taken as confirmation of this estimate.

The uncertainties in the measurements made in this experiment are believed to be largely statistical, namely the statistics of the measured left right ratio and of the ratio for the thick $C D_{2}$ which entered through the thickness correction. Other.sources of error were smaller by comparison. The statistical errors were combined with the quoted error on the $\mathrm{Mg} \mathrm{P}_{2}$ as independent errors to calculate the error in $\mathrm{P}_{1}$ listed in Table V. 


\section{CONCLUSIONS}

This experiment has shown that the neutrons from the photodisintegration of deuterium by 2.753-Mev gamma rays are negatively polarized. The sign, magnitude, and angular dependence of the polarization are in agreement with the theoretical prediction, verifying the assumptions of the theory within the experimental uncertainties. These assumptions were that only magnetic dipole and electric dipole transitions are important at this energy and that only central nuclear forces are involved. The parameters derived from effective range theory gave a satisfactory fit tin the data. The present results providc confirmation for the theory of the low-energy photodisintegration of the deuteron derived from cross-section measurements:

In the future, it should be possible to improve on the present results. especially by using thinner deuterium sources. In addition, the same setup can be used to measure the polarization of the photoneutrons from beryllium by replacing the magnesium with a scatterer having a suitable resonance.

\section{ACKNOWLEDGEMENTS}

It is a pleasure to acknowledge our great indebtedness to $D r$. $A$. $T$ 。 Elwyn, Dr。 R. O. Lane, and Dr。A.S, Langsdorf, J r。 for communicating their magnesium results to us before publication and for helpful discussions. Their kind cooperation was essential to the analysis of our results. Many helpful discussions were held with Dro.J.Sawicki concerning theoretical questions. We thank Dr.G.Kramer for performing the effective-range calculation and for valuable discussions. Mro. $R_{0}$. Jewell assisted with some of the experimental runs. The staff of the LPTR gave us much assistance, paro ticularly in the handling of the kilocurie sources. We thank Dr。A.J.Kirschbaum for his generous support of this experiment. 


\section{REFERENCES}

* This work was done under the auspices of the U.S. Atomic Energy Commission.

${ }^{1}$ B. T. Feld, B. C. Maglic, and J. Parks, Suppl. Nuovo cimento XVII, -No. 2, $241(1960)$.

2 L. N. Rosentsveig, Physica 22, 1182 (1956)。

${ }^{3}$ W. Czyz and J. Sawicki, Physica 22, 1182 (1956)。

${ }^{4}$ L. N. Rosentsveig, J. Expt1. Theoret. Phys. (U.S.S.R.) 31, 166 (1956), [translation: Soviet Phys. JETP 4, 280 (1957)].

${ }^{5}$ W: Czyz and J. Sawicki, Nuovo cimento 5, 45 (.1957); Phy.s. Rev. 110, $900(1958)$.

${ }^{6}$ M. Kawaguchi, Phys. Rev. 111, 1314 (1958).

7 J.J. de Swart, W. Czyz, and J. Sawicki, Phys.Rev: Letters 2, 51 (1959).

${ }^{8}$ M. L. Rustgi, W. Zernik, G. Breit, and D. J. Andrews, Phys. Rev. 120, $1881(1960)$.

${ }^{9}$ G. Kramer and D. Müller, Z. Physik 158, 204 (1960).

${ }^{10}$ G. Kramer, private communication.

${ }^{11}$ E. L. Chupp, R. W. Jewell, Jr., and W. John, Phys. Rev. 121, 234 (1961).

12 A. Hedgran and D.E. Lind, Arkiv Fysik 5, 177 (1952); private communication quoted in preprint by J. E. Monahan, S. Raboy, and C. C. Trail, 1961.

${ }^{13}$ Nuclear Data Sheets published by National Academy of Sciences - National Research Council, Washington, D. C. 
${ }^{14}$ E. Amaldi, Handbuch der Physik (Springer, Berlin - Gottingen - Heidelberg, 1959), Bd. XXXVIII.

${ }^{15}$ R. E. Fields and M. Walt, Phys. Rev. 83, 479 (1951).

${ }^{16}$ H. W. Newson, R. C. Block, P. F. Nichols, A. Taylor, and A. K. Furr, Ann. Phys. 8, 211 (1959).

${ }^{17}$ A. J. Elwyn and R. O. Lane, Bull. An. Phyo. Soc.Ser.II, 5, 410 (1960).

${ }^{18}$ A. J. Elwyn, R. O.: Lane, and A. S. Langsdorf, Jr., private communication.

19 J. V. Lepore, Phys.. Rev. 79, 137 (1950).

20 J. J. de Swart, Physica 25, 233 (1959).

${ }^{21}$ S. E. Darden, preprint.

22 L. Hulthen and M. Sugawara, Handbuch der Physik (Springer, Berlin Gottingen - Heidelber.g, 19.57), Bd。XXXIX。

${ }^{23}$ G. R. Bishop; L. E. Beghian, and H. Halban, Phys. Rev. 83, 1052 (1951). 
This report was prepared as an account of Government sponsored work. Neither the United States, nor the Commission, nor any person acting on behalf of the Commission:

A. Makes any warranty or representation, expressed or implied, with respect to the accuracy, completeness, or usefulness of the information contained in this report, or that the use of any information, apparatus, method, or process disclosed in this report may not infringe privately owned rights; or

B. Assumes any liabilities with respect to the use of, or for damages resulting from the use of any information, apparatus, method, or process disclosed in this report.

As used in the above, "person acting on behalf of the Commission" includes any employee or contractor of the Commission, or employee of such contractor, to the extent that such employee or contractor of the Commission, or employee of such contractor prepares, disseminates, or provides access to, any information pursuant to his employment or contract with the Commission, or his employment with such contrartor. 